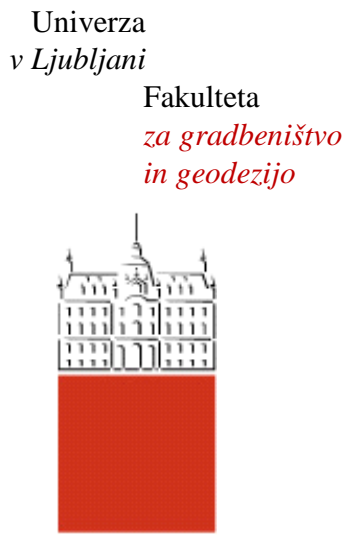

Jamova 2

1000 Ljubljana, Slovenija http://www3.fgg.uni-lj.si/

DRUGG - Digitalni repozitorij UL FGG http://drugg.fgg.uni-lj.si/

Ta članek je avtorjeva zadnja recenzirana različica, kot je bila sprejeta po opravljeni recenziji.

Prosimo, da se pri navajanju sklicujete na bibliografske podatke, kot je navedeno:

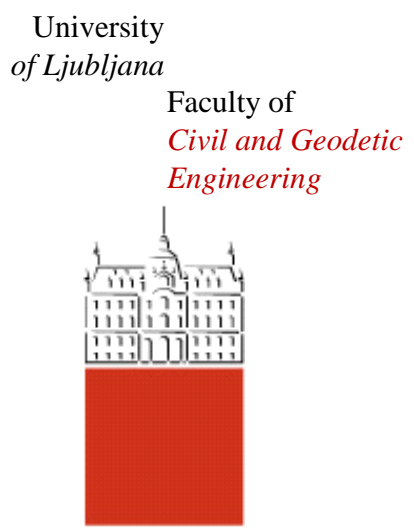

Jamova 2

SI - 1000 Ljubljana, Slovenia http://www3.fgg.uni-lj.si/en/

DRUGG - The Digital Repository http://drugg.fgg.uni-lj.si/

This version of the article is author's manuscript as accepted for publishing after the review process.

When citing, please refer to the publisher's bibliographic information as follows:

Trtnik, G., Valič, M. I., Kavčič, F. in Turk, G. 2009. Comparison between two ultrasonic methods in their ability to monitor the setting process of cement pastes. Cement and Concrete Research 39, 10: 876-882.

DOI: 10.1016/j.cemconres.2009.07.002. 


\title{
Comparison between two ultrasonic methods in their ability to monitor the setting process of cement pastes
}

\author{
Gregor Trtnik $^{\text {a,b }}$, Marko Ivan Valic ${ }^{c}$, Franci Kavčič ${ }^{b}$, Goran Turk ${ }^{a^{*}}$ \\ ${ }^{a}$ University of Ljubljana, Faculty of Civil and Geodetic Engineering, Jamova 2, 1000 Ljubljana, Slovenia \\ ${ }^{\mathrm{b}}$ IGMAT d.d., Building Materials Institute, Polje 351c, Ljubljana, Slovenia \\ ${ }^{\mathrm{c}}$ University of Ljubljana, Faculty of Maritime and Transport Studies, Pot Pomorščakov 4, 6320 Portorož, \\ Slovenia
}

\begin{abstract}
This paper presents the comparison between ultrasonic wave transmission (USWT) method and ultrasonic wave reflection (USWR) method in their ability to monitor the setting process of cement pastes. The velocity of ultrasonic longitudinal waves and shear wave reflection coefficient were measured simultaneously on cement pastes with different hydration kinetics. Even though both methods are able to reliably monitor the hydration process and formation of structure of an arbitrary cement paste, they monitor the setting process in different ways. The relationship between the velocity of longitudinal waves and shear wave reflection coefficient can be simplified into three characteristic phases and the end of the first phase can be used to define the beginning of the setting process of cement paste.
\end{abstract}

Keywords: Cement paste; Hydration; Ultrasonic wave transmission method; Ultrasonic wave reflection method; Setting.

\section{Introduction}

Acoustic waves are being used successfully to monitor the setting and hardening process of different cement-based materials. Two types of waves are generally used, namely shear waves (s-waves) and longitudinal waves (p-waves). Numerous attempts have been done in order to investigate the relationship between the ultrasonic measurements and some properties of different cement-based materials.

The ultrasonic shear wave reflection method was first applied to the area of cementitious materials by Stepišnik et al. [1] and has been advanced further by Valič [2]. This method can be used to monitor the strength development of cementitious materials at early age [3-5]. By using shear waves, the measurements can be correlated to the shear module and viscosity, which are parameters of interest for

\footnotetext{
${ }^{*}$ Corresponding author. Phone: +38614768 614; fax: +38614768629

Email address: gturk@fgg.uni-lj.si
} 
most engineers and researchers [6]. A linear relationship was found between degree of hydration and reflection loss [7].

Reinhardt and Grosse [8,9] evaluated changes in the material properties associated with concrete aging by measuring the velocity of longitudinal waves, signal shapes of transmitted waves, and their frequency spectra and very recently, some studies have been done in order to correlate the initial setting time of different cement based materials and the velocity of ultrasonic longitudinal waves [10-12]. Krauss and Hariri [13] presented the procedure to determine the end of the dormant phase and initial degree of hydration by the ultrasonic wave transmission method.

However, little research has been done in the analysis of the correlation between the velocity of ultrasonic longitudinal and shear waves and the comparison between ultrasonic wave transmission and ultrasonic wave reflection method to monitor the hydration process and formation of structure of cement-based materials. Voigt et al. [14] presented comparison of ultrasonic wave transmission and reflection measurements with longitudinal and shear waves on early age mortar and concrete. They indicated that these two ultrasonic methods monitor the setting process of mortar and concrete in significantly different ways.

The objective of this paper was to study the correlation between the ultrasonic wave transmission method (USWT) and ultrasonic wave reflection method (USWR) in their ability to monitor the setting process of different cement pastes. Therefore, a comprehensive experimental work has been performed. The evolution of the velocity of ultrasonic longitudinal waves, $v_{p}$, and shear wave reflection coefficient, $r$, with time, $t$, were measured simultaneously on different cement pastes in order to get the most appropriate correlation between $v_{p}$ and $r$. The influence of water/cement ratio (w/c), environmental temperature (T), cement type (CT), cement fineness (BS), and amount of $\mathrm{C}_{3} \mathrm{~A}(\mathrm{C} 3 \mathrm{~A})$ on the $v_{p}-r$ relationship was studied. As an addition, the possibility of using this combined ultrasonic method to estimate the beginning of the setting process of cement paste is also discussed.

\section{Experimental methods}

\subsection{Wave transmission method}

The Proceq CCT4 set up was adequately electronically modified to measure the $v_{p}$ automatically with any pre-selectable intervals after casting. This fully automated determination of the initial onset of the signal is of special significance to routine industrial application. The apparatus consists of a waveform generator board and two broadband transducers (Tx, Rx) of central frequency of $54 \mathrm{kHz}$ and $25 \mathrm{~mm}$ in diameters. It was connected to the PC computer and special software was prepared in order to collect the velocity $v_{p}$ data with time. Cubic specimens sized $80 \times 80 \times 80 \mathrm{~mm}^{3}$ were used and the length of the straight-wave-path through the specimen was $70 \mathrm{~mm}$ in this study. The $v_{p}$ measurements started immediately after casting and continued for 30 hours. The results were recorded at 1 min intervals. Detailed description of the USWT method used in this study can be found in ref. [11]. 


\subsection{Wave reflection method}

A model of an apparatus using the pulse USWR method has been already briefly described by Valič [2]. In the exploration studies of the method and in particular of the apparatus several ideas for improvements came out. The corresponding modifications were implemented in a new apparatus, USWR-4 Hardening meter. Its basic components are: main frame box with transmitter/receiver electronics, A/D converter board and power supply, the measuring heads, and PC computer with suitable software. Measuring head is of rugged construction and consists of a cylindrical aluminium body $(\Phi=30, l=40 \mathrm{~mm})$ in which a very pure fused quartz rod of rectangular cross-section $(a=10, b=16 \mathrm{~mm})$ and length $l=50 \mathrm{~mm}$ is rigidly fastened. The two end surfaces of the quartz rod are flat, very parallel and highly polished. On one end (bottom) a PZE ultrasound transducer, acting as a transmitter and receiver, is hard bonded. On the other end (top), with a measuring surface of $2 \mathrm{~cm}^{2}$, the sample to be tested is smeared.

Hydration/hardening process quite often last very long and the multitude/complexity from the influential parameters is high. For this reason, USWR-4 Hardening meter is constructed in a multi-head version with four measuring heads operating simultaneously. For temperature hydration/hardening dependence studies the measuring head as a whole could be inserted in a variable temperature oven. Detailed description of the principles of operation and performance of the apparatus can be found in ref. [2].

Within the present study all reflection coefficient measurements started immediately after casting and continued for at least 30 hours. The results were recorded at 1 min intervals.

\section{Experimental program}

\subsection{Materials}

Ten cement pastes were prepared in order to achieve the objective of this study. Four types of Portland cements were used (Table 1), produced by Salonit Anhovo. In the table AC stands for the clinker content in each cement type.

\section{Table 1}

Characteristics of cement types used in the study.

\begin{tabular}{cccccccc}
\hline cement type & label & $\mathrm{AC}[\%]$ & $\mathrm{BS}\left[\mathrm{cm}^{2} / \mathrm{g}\right]$ & $\mathrm{C}_{3} \mathrm{~S}[\%]$ & $\mathrm{C}_{2} \mathrm{~S}[\%]$ & $\mathrm{C}_{3} \mathrm{~A}[\%]$ & $\mathrm{C}_{4} \mathrm{AF}[\%]$ \\
\hline CEM II/A-S, 42.5R & $\mathrm{C} 1$ & $>80$ & 4260 & 32.85 & 46.32 & 10.36 & 10.47 \\
CEM I, 42.5 N & $\mathrm{C} 2$ & $>95$ & 2640 & 60.20 & 13.60 & 7.20 & 9.30 \\
CEM I, 42.5 N SR & $\mathrm{C} 3$ & $>95$ & 3130 & 55.90 & 21.90 & 2.30 & 15.00 \\
CEM I, 52.5 R & $\mathrm{C} 4$ & $>95$ & 4310 & 57.70 & 13.00 & 6.90 & 8.90 \\
\hline
\end{tabular}

In Table 2 the relevant characteristics of all ( 8 in total) mixtures used in this study are given. In the last column the sample temperature during measurements are added. In order to get three different values of cement fineness, cement types $\mathrm{C} 2$ and $\mathrm{C} 4$ were used separately and one mixture (namely MF3) was prepared by mixing these two cements in the ratio of 50/50. This can be done because of very similar 
chemical composition of these three cements. A similar procedure was used in order to obtain three different values of $\mathrm{C}_{3} \mathrm{~A}$ content. Cement types $\mathrm{C} 2$ and $\mathrm{C} 3$ were used for this purpose.

Table 2

Influential parameters of cement paste mixtures used in the study.

\begin{tabular}{|c|c|c|c|c|c|c|c|}
\hline No. & Mixture label & & $\mathrm{CT}$ & $\mathrm{w} / \mathrm{c}$ & $\mathrm{BS}\left[\mathrm{cm}^{2} / \mathrm{g}\right]$ & $\mathrm{C}_{3} \mathrm{~A}[\%]$ & $\mathrm{T}\left[{ }^{\circ} \mathrm{C}\right]$ \\
\hline 1 & MC1035 & & $\mathrm{C} 1$ & 0.35 & 4260 & 10.36 & 21 \\
\hline \multirow[t]{2}{*}{2} & MC1040 & & $\mathrm{C} 1$ & 0.4 & 4260 & 10.36 & 21 \\
\hline & & MT1 & $\mathrm{C} 1$ & 0.5 & 4260 & 10.36 & 21 \\
\hline \multirow[t]{2}{*}{3} & MC1050 & MT2 & $\mathrm{C} 1$ & 0.5 & 4260 & 10.36 & 26 \\
\hline & & MT3 & $\mathrm{C} 1$ & 0.5 & 4260 & 10.36 & 32 \\
\hline 4 & MC2, MF1, MC3A1 & & $\mathrm{C} 2$ & 0.5 & 2640 & 7.20 & 21 \\
\hline 5 & MC3, MC3A2 & & $\mathrm{C} 3$ & 0.5 & 3130 & 2.30 & 21 \\
\hline 6 & MC4, MF2 & & $\mathrm{C} 4$ & 0.5 & 4310 & 2.60 & 21 \\
\hline 7 & MF3 & & $\mathrm{C} 2, \mathrm{C} 4$ & 0.5 & 3490 & 7.10 & 21 \\
\hline 8 & MC3A3 & & $\mathrm{C} 2, \mathrm{C} 3$ & 0.5 & 2805 & 4.80 & 21 \\
\hline
\end{tabular}

\subsection{Reproducibility of the measurements}

To examine reproducibility of both ultrasonic methods, the tests on mixtures MC1035 (USWT method) and MC1050 (USWR method) were repeated 7 - and 4 - times, respectively. The results measured with the two methods are presented in Figs. $1 \mathrm{a}$ and $1 \mathrm{~b}$. It can be seen from these figures that the inherent scattering in these tests is rather small and the equipment's reproducibility very high. Note: instead of the time dependence of the reflection coefficient $r(t)$, its compliment, its change $d r(t)[=1-r(t)]$ is plotted in all USWR figures in the study. In this way the USWR curves resemble the hydration and hardening growth with time. Based on the definition of the reflection coefficient, both $r$ and $d r$ values are expressed without units [2].

a)

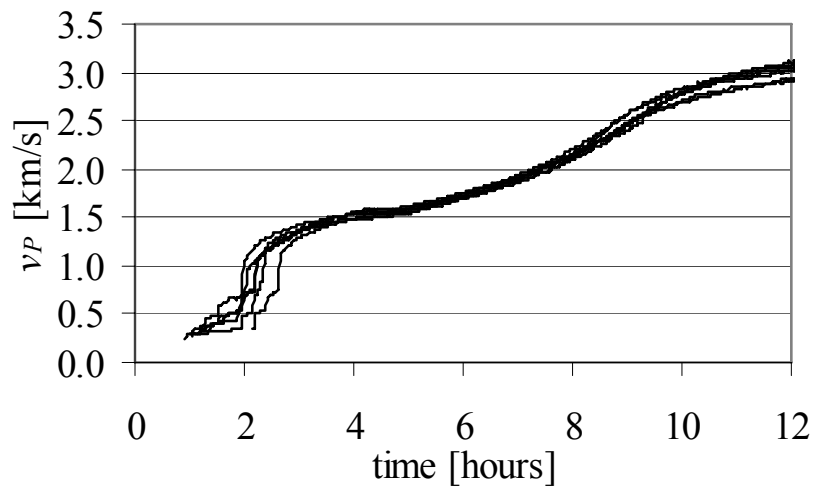

b)

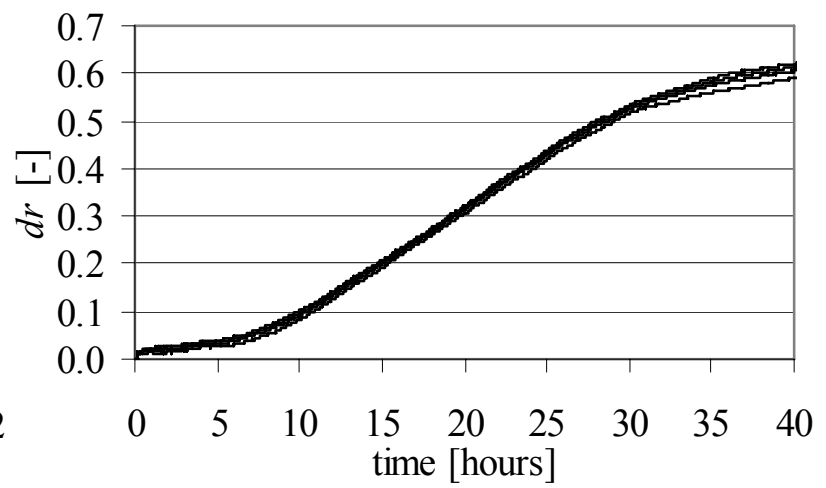

Fig. 1. Reproducibility of both ultrasonic methods used in the study, a) USWT, b) USWR. 
In Fig. 1a, a little higher inherent scattering is observed at the very beginning of the hydration process. This phenomenon corresponds mainly to the small deviation in the initial distance between the two broadband transducers. After some time, all USWT curves were almost identical. It should also be pointed out USWT curves do not start from $t=0$ like USWR counterpart. Due to large internal damping of p-waves reach the receiving sensor with sufficient amplitude to be detected after a certain time which depends, apart from the Tx-Rx sensor separation and output power of Tx pulse, also on the sample parameters, e.g. w/c ratio, sample temperature, cement fineness, cement type, cement fineness, and content of $\mathrm{C}_{3} \mathrm{~A}$.

\section{Experimental results}

\subsection{Sensitivity of USWT and USWR methods to monitor the setting process}

Fig. 2 presents the sensitivity of USWT and USWR methods on the hydration process and formation of internal rigid structures in different cement pastes. It can be seen from Figs. $2 a$ and $2 b$ that mixtures with a higher w/c ratio show lower values of $v_{p}$ and $d r$. In these experiments the temperature for the three samples was kept the same (T1). Further, from Figs. $2 \mathrm{c}$ and $2 \mathrm{~d}$ it is seen that higher environmental temperatures result in a more rapid increase of $v_{p}$ and $d r$ values. In these experiments the sample composition is the same, namely MC1050. Interestingly, the USWR method is more sensitive to the change of the curing temperature than the USWT counterpart. A well known cross-over effect can be clearly seen from figure $2 \mathrm{~d}$ which was also observed by some other researchers in their studies of the influence of the curing temperature on the development of concrete compressive strength and adiabatic hydration curves $[15,16]$. Figs. 2e and $2 \mathrm{f}$ present the influence of the cement type on the evolution of $v_{p}-$ $t$ and $d r-t$ curves. As expected, cement type has a significant influence on the evolution of both $v_{p}$ and $d r$ values. The sensitivity of the USWR method is more pronounced. The influence of the cement fineness on the evolution of $v_{p}$ and $d r$ values with time can be seen in Figs. $2 \mathrm{~g}$ and $2 \mathrm{~h}$. It is well known that higher fineness leads to a faster hydration process and consequently to the more rapid evolution of $v_{p}$ and $d r$. The sensitivity of both techniques is comparable in this case. Figs. $2 \mathrm{i}$ and $2 \mathrm{j}$ demonstrate the influence of the amount of tri-calcium aluminate $\left(\mathrm{C}_{3} \mathrm{~A}\right)$ together with the influence of cement fineness (see Table 2). Even though cement type $\mathrm{C} 4$ has higher fineness than cement type $\mathrm{C} 3$ it has a lower amount $\mathrm{C}_{3} \mathrm{~A}$, which finally results in the slower evolution of both $v_{p}$ and $d r$ values.

It can be seen from Fig. 2 that both USWT and USWR methods are able to reliably monitor the hydration process and formation of rigid structures in all cement pastes, used in this study. The effects of cement paste initial parameters on the hydration process of cement-based materials are in good accordance with the well known rules of mix proportioning and other initial characteristics of fresh cement paste mixture, observed by some other researchers [15-17]. Therefore, it can be concluded that measurements with both USWT and USWR method conducted on cement pastes with different hydration kinetics, evaluated on a qualitative basis, yield similar results. 
a)

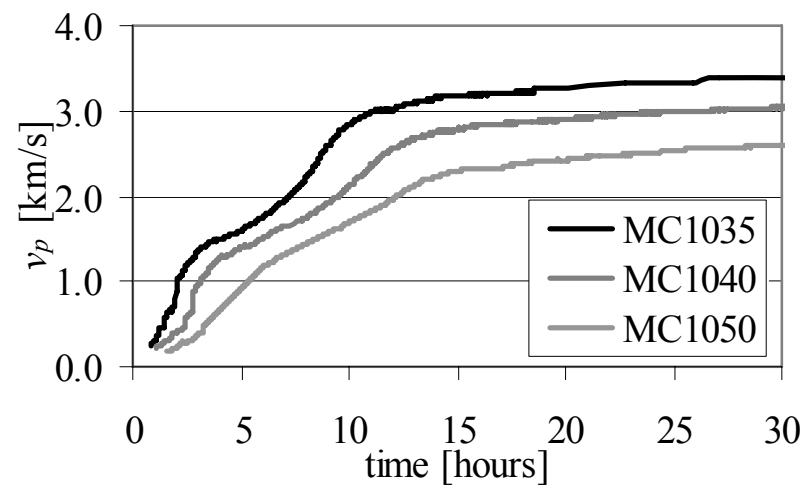

c)

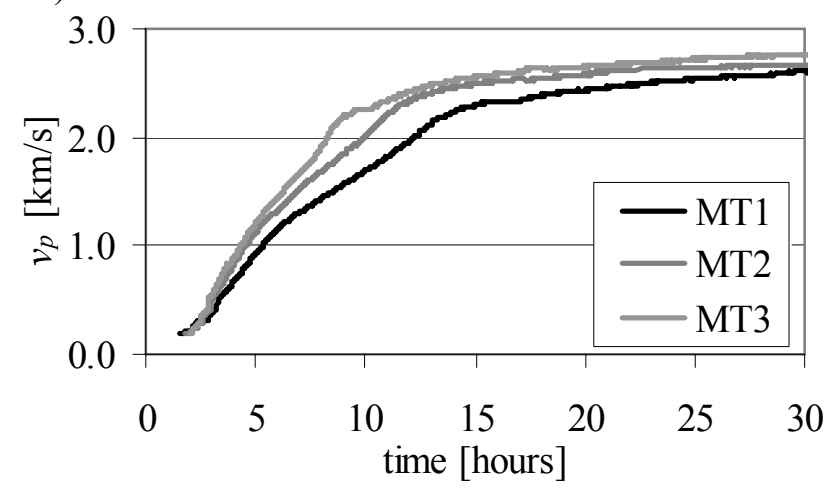

e)

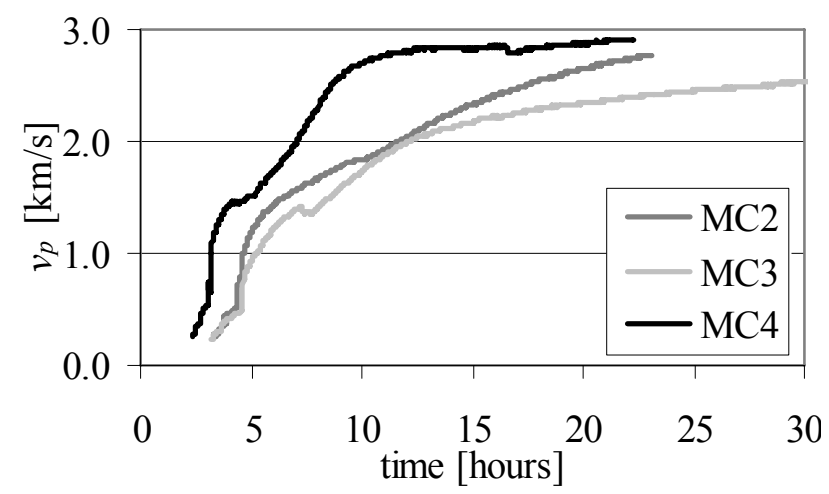

g)

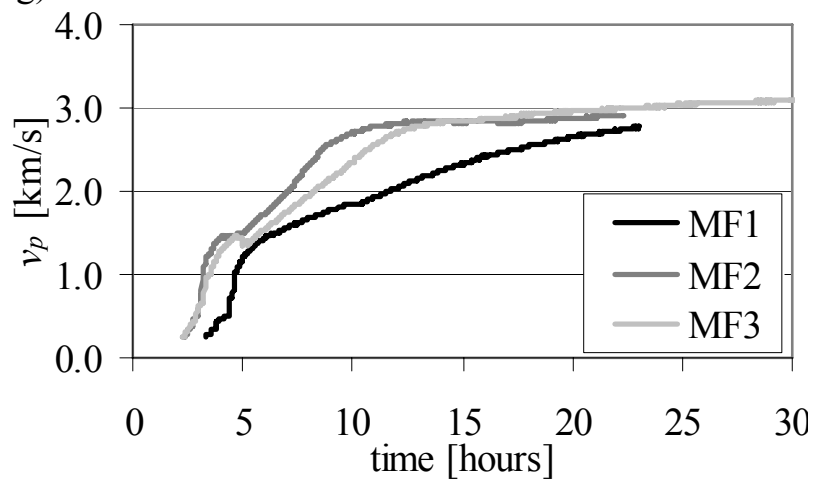

b)

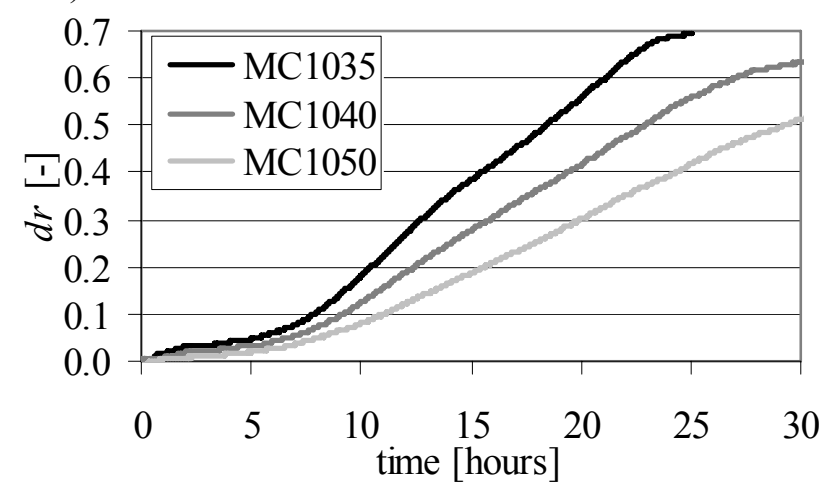

d)

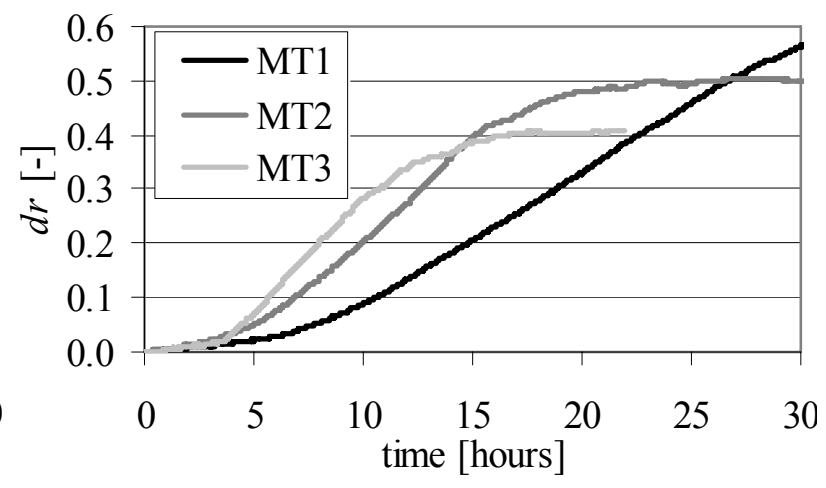

f)

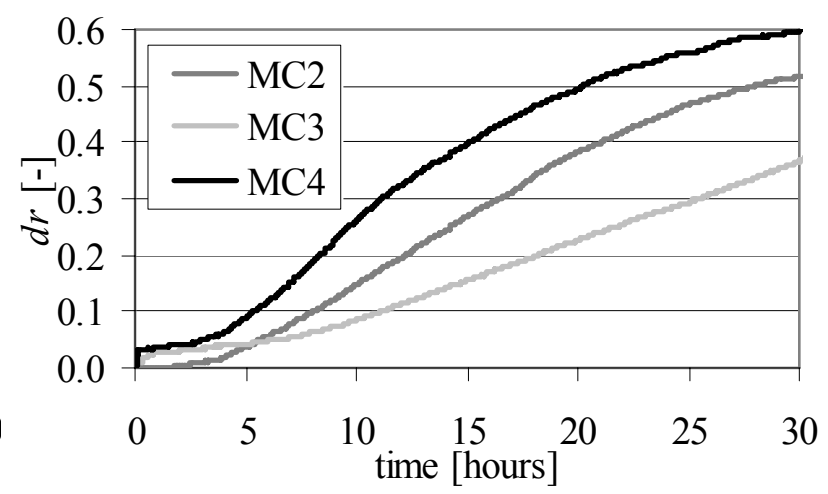

h)

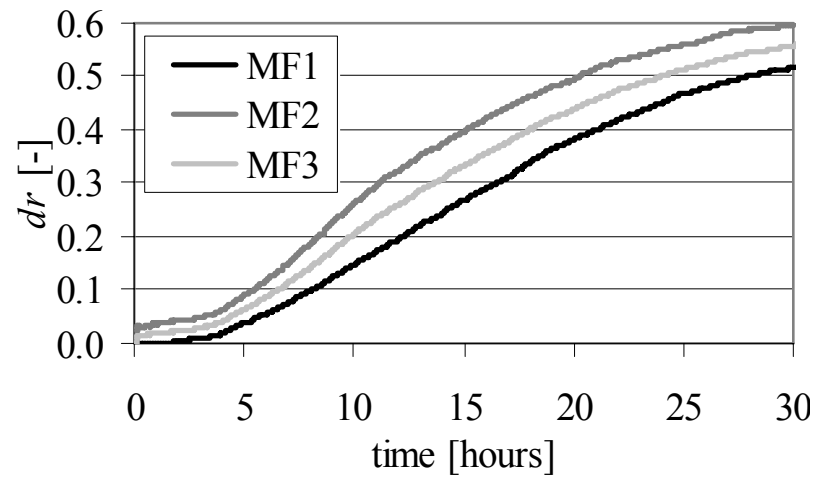


i)

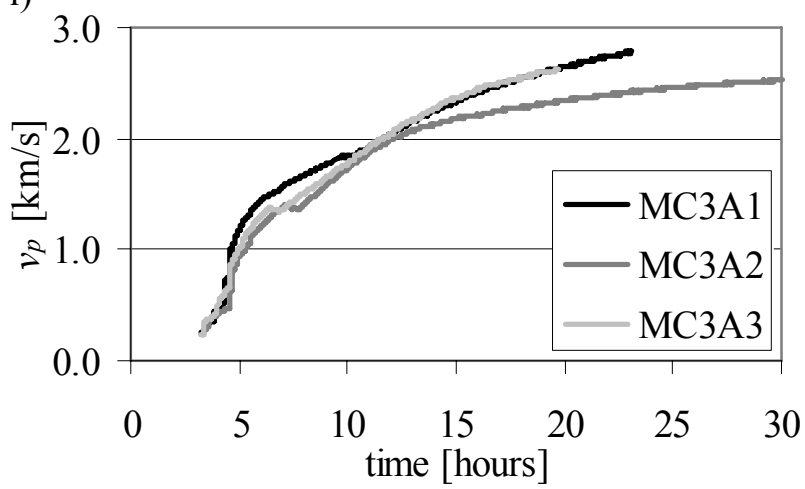

j)

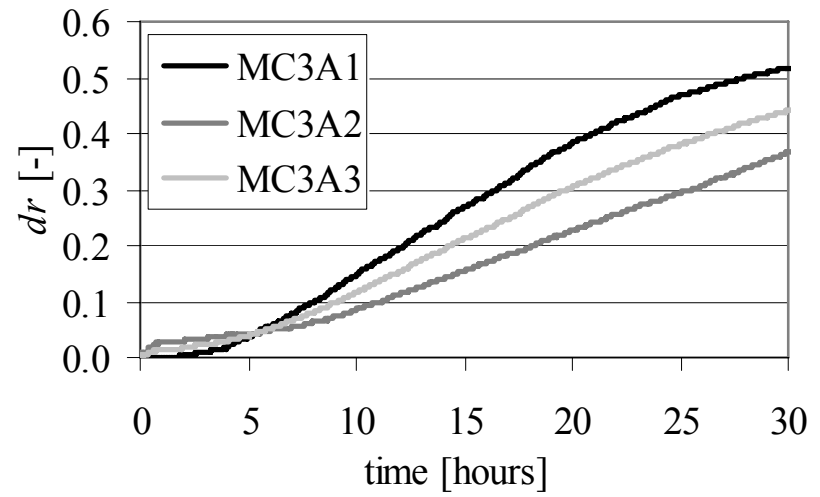

Fig. 2. Comparison of sensitivity of USWT and USWR methods to the influence of different parameters on hydration process of cement pastes; w/c ratio $(a, b)$, curing temperature $(c, d)$, cement type $(e, f)$, cement fineness (g,h), and cement composition (i,j).

\subsection{Correlation between $v_{p}$ and $d r$ values for different cement pastes}

In order to achieve the objective of this study comparisons of the general evolution of $v_{p}-t$ and $d r-t$ curves have to be analyzed in more details first. In Figs. $3 \mathrm{a}$ and $3 \mathrm{~b}$ the $v_{p}-t$ and $d r-t$ curves together with their numerical derivatives $\left(v_{p}{ }^{\prime}-t\right.$ and $\left.d r^{\prime}-t\right)$ for the same cement paste MC1035 (Table 2) are presented.

a)

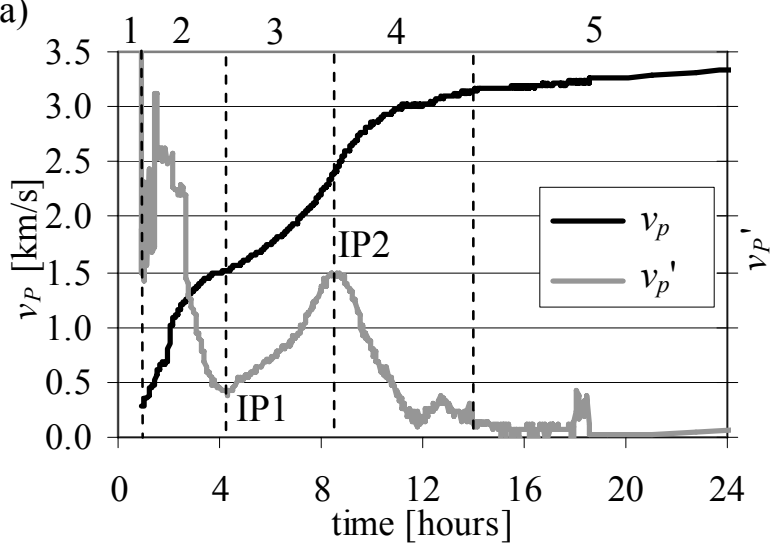

b)

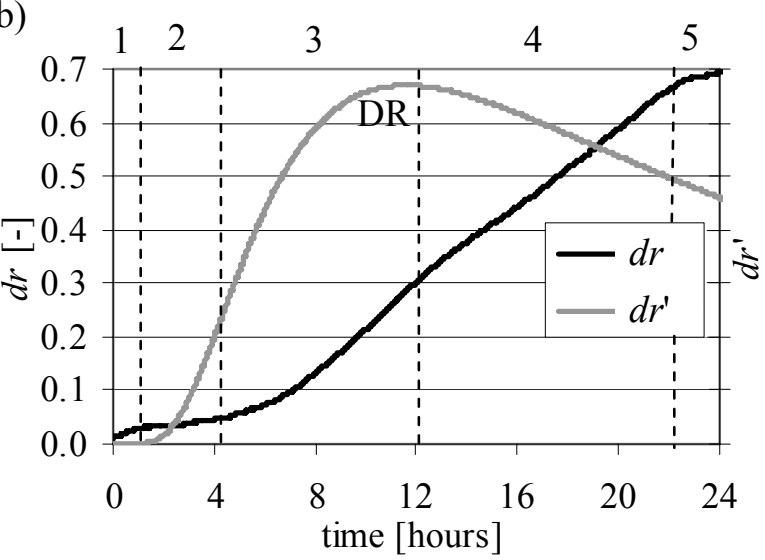

Fig. 3. Time evolution of hydration curves (mixtures MC1035); a) $v_{p}-t$ and $v_{p}{ }^{\prime}-t$ curves, b) $d r-t$ and $d r^{\prime}-t$ curves.

It is seen from Figs. 3 that both USWT and USWR curves can be divided into five stages. Considering first the results in Fig. $3 \mathrm{a}$ in the first stage the sound speed $v_{p}$, as pointed out already, could not be measured with the USWT experimental set-up used. It could only be measured after expiring of a certain time from the sample preparation during which the internal damping decreases to a sufficiently low value. From that point on relatively low values of sound speed $v_{p}$ are observed in the second stage of which upper bound is the first inflection point IP1 on the $v_{p}-t$ curve. Observations of low speed initial values have been also reported and discussed by other researchers [12, 18-20]. The time from the initial start of hydration to the first inflection point is designated as $t_{I P I}$. The third stage extends up to the second inflection point IP2 at which the hydration process causing the fast increase in speed of sound begins 
slows down. The IP2 point defines the beginning of the stage 4 in this study which is extending until a plateau is reached [21]. From then a long duration stage 5 follows in which speed of sound $v_{p}$ continuously and very slowly increases with time. Inflection points become clearly distinctive in the derivative curves included in all diagrams in Fig. 3.

Considering now the USWR results in Fig. $3 \mathrm{~b}$, the $d r-t$ curve can also be divided into five stages. In the stage 1 the finest cement grains hydrate in a very short period. This stage is not detected with USWT method. In the stage 2 (induction stage) a short plateau is reached after which, in stage $3, d r$ values start to increase slowly at first and faster later to a hardly distinctive inflection point DR. After the inflection point the rate of $d r$ increase slows down somewhat, but continues (stage 4) until a new plateau is reached. From there on stage 5 follows.

It follows from the preceding results, that both USWT and USWR methods are able to monitor the hydration processes of cement pastes. However, the results reveal that, originating from the different propagation properties of the $\mathrm{p}$ - and s-waves in a medium, the two ultrasonic methods monitor the setting processes of cement pastes in different ways. In Fig. 4 the relationships between $v_{p}$ and $d r$ values for all cement paste mixtures studied are presented. These diagrams were obtained from Figs. 2 by plotting $d r$ vs. $v_{p}$ values at equal times $t$. Noticeably and not surprisingly the $d r-v_{p}$ curves in all diagrams of Fig. 4 are not equal for all cement pastes. There are larger and smaller discrepancies or the curves take similar course during certain stage. Far the largest deviations are produced by the amount of water added (Fig. 4a). Also, the slopes of $d r-v_{p}$ curves change significantly. It follows that USWT and USWR methods applied are not sensitive to the effects of cement paste initial parameters and of internal structures developing during hydration to the same degree. Included on each $d r-v_{p}$ curve are some characteristic inflection points (IP1, IP2, DR) discussed in more details in the following chapter. 
a)

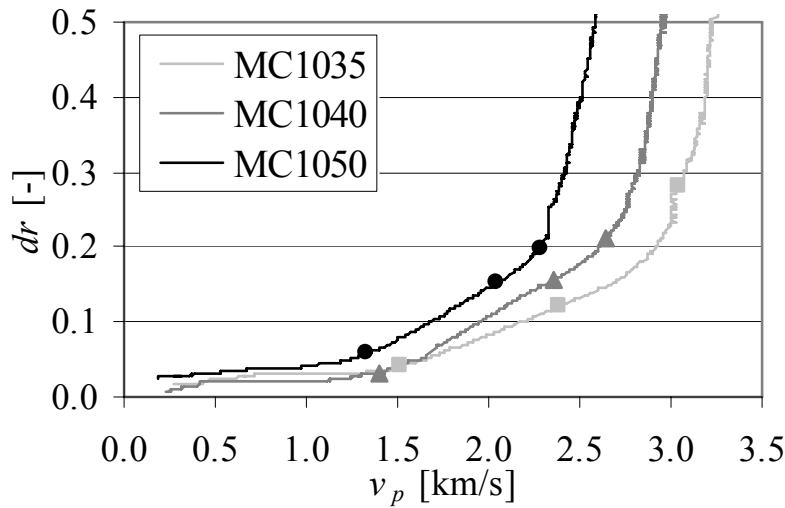

c)

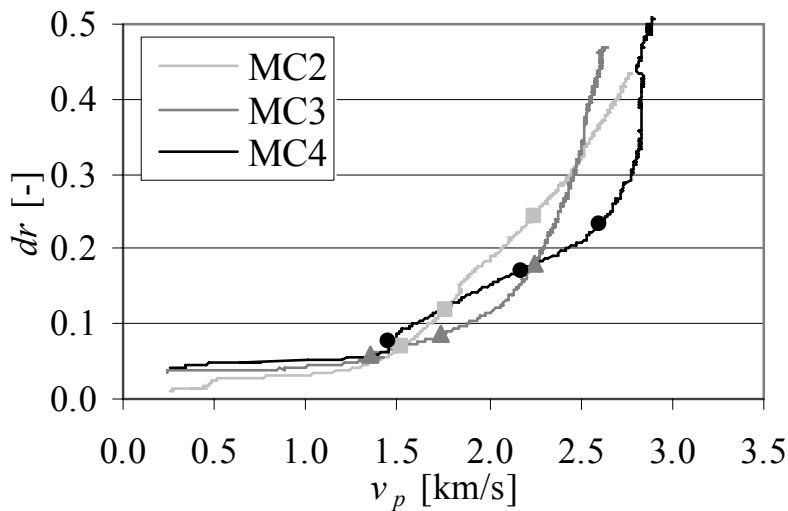

e)

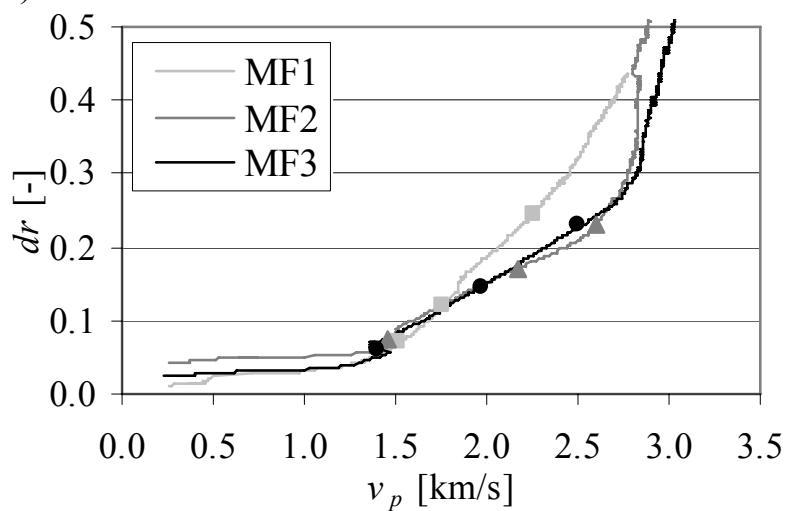

b)

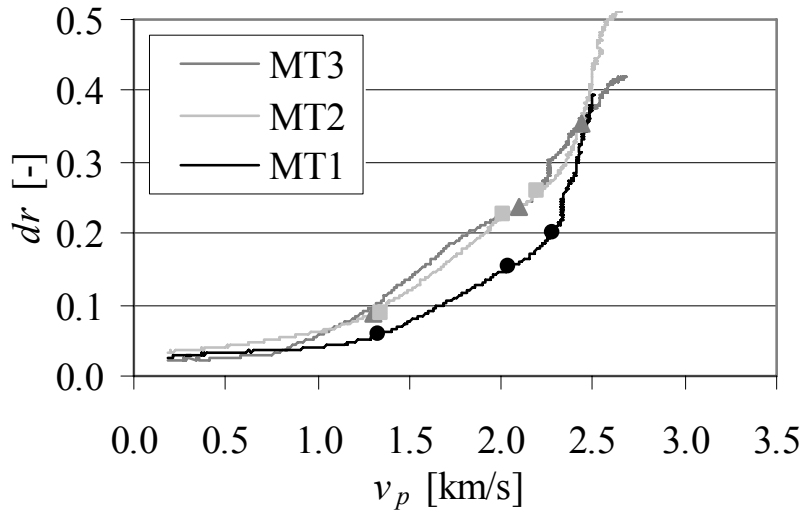

d)

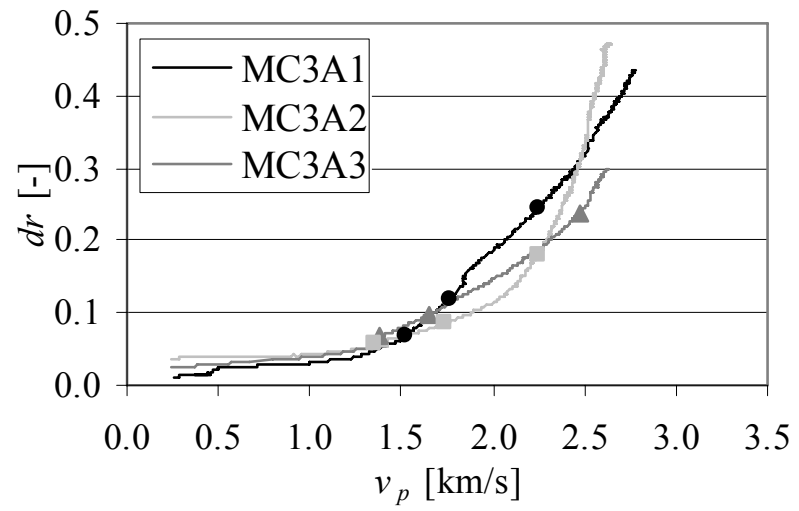

Fig. 4. $d r-v_{p}$ relationships for all cement pastes, used in this study influenced by: a) w/c ratio, b) curing temperature, c) cement type, d) cement composition, e) cement fineness.

\subsection{Characteristic points on the $d r-v_{p}$ curves}

On each of the experimental results in Fig. 2 some characteristic inflection points can be defined, two (IP1, IP2) and one (DR) on each $v_{p}-t$ and $d r-t$ curve, respectively, by way of example shown in Fig. 3. The inflection points so found are entered also in each of $d r-v_{p}$ curves of Fig. 4. All of these $d r-v_{p}$ curves can be simplified into 3 characteristic phases as shown in Fig. 5. In phase 1 large increases of the ultrasonic pulse velocity of p-waves can be observed. On the other hand, the initial values of shear wave 
reflection coefficient do not change appreciably during this phase. This observation is indicated by an almost horizontal line in each $d r-v_{p}$ curve in phase 1. This indicates that $v_{p}$ is very sensitive to the internal structures in cement pastes even before the initial setting time. It is well known that $v_{p}$ speed is strongly affected by the formation of ettringite crystals [21], which develop during the early age of the hydration process $[15,22]$. On the other hand formation of new internal structures in cement pastes do not seem to influence the shear wave reflection coefficient appreciably, which is in good agreement with the results presented by Voigt et al. [4]. This originates from the fact that s-waves can not propagate through the suspension state of cement paste mixtures at the very beginning of the hydration process.

With continuing hydration the amount of solid products and the amount of connected solid phase increases rapidly [21]. Consequently, both $v_{p}$ and $d r$ values increase greatly during phase 2 as indicated by the steeper slope of the line during this phase on each of the $d r-v_{p}$ curves. When the amount of solid phase reaches a certain value, the rate of increase of $v_{p}$ values slows down while the values of $d r$ continue to increase appreciably. This is indicated by almost vertical line during phase 3 of the $d r-v_{p}$ curve in Fig. 5.

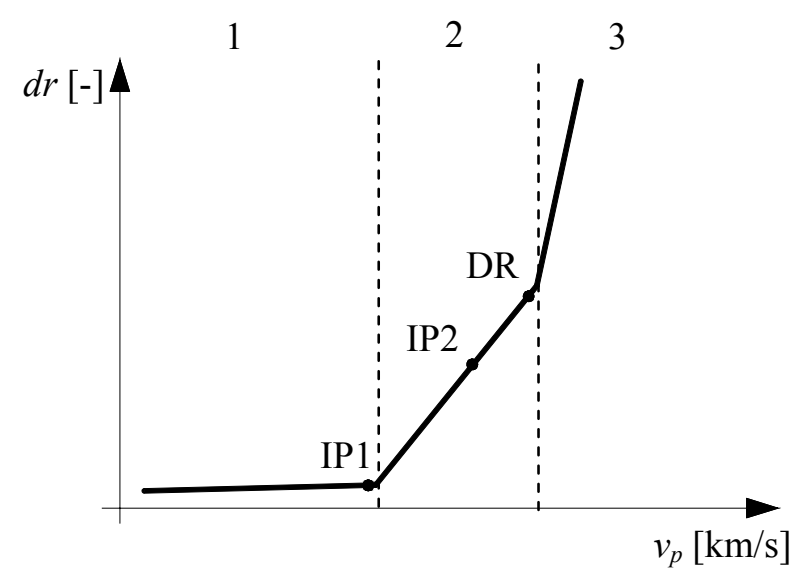

Fig. 5. Simplification of $d r-v_{p}$ curves into three characteristic phases.

Included in Table 3 are the times $t_{i}(i=\mathrm{IP} 1, \mathrm{IP} 2, \mathrm{DR})$ from the initial start of hydration to the individual inflection point (IP1, IP2, DR) and $v_{p i}$ and $d r_{i}$ the corresponding values of $v_{p}$ and $d r$ at all characteristic points shown on each $d r-v_{p}$ curve in Fig. 4. From this figure it can be seen that the first inflection point IP1 corresponds quite well with the end of the first phase on the $d r-v_{p}$ curves. Moreover, the $v_{P I P I}$ values, the values of $v_{p}$ at the times $t_{I P I}$ (Table 3), are quite similar for all cement paste mixtures used in this study. The average value of $v_{P I P I}$ is $1410 \mathrm{~m} / \mathrm{s}$. Next, it can be noticed that IP2 points occur within the phase 2 of the $d r-v_{p}$ curves, while DR points appear more or less at the end of this second phase. This indicates that the maximum rate of $v_{p}$ evolution, occurring at the second inflection point IP2, appears earlier than the maximum rate of $d r$ evolution in all cement paste mixtures (Table 3). Moreover, when the maximum rate of $d r$ evolution appears, the evolution of $v_{p}$ has almost reached the plateau value.

Finally, the times $\left(t_{I P 1}, t_{I P 2}, t_{D R}\right)$ are shorter in the case of cement type $\mathrm{C} 2$, lower w/c ratio, higher curing temperature, higher cement fineness, and higher amount of $\mathrm{C}_{3} \mathrm{~A}$. 
Table 3

Characteristics of IP1, IP2, and DR inflection points for all cement paste mixtures, used in his study

\begin{tabular}{|c|c|c|c|c|c|c|c|c|c|c|}
\hline \multirow{2}{*}{$\begin{array}{c}\text { mixture } \\
\text { label }\end{array}$} & & \multicolumn{3}{|c|}{ characteristic times [hours] } & \multicolumn{3}{|c|}{ values $v_{p}[\mathrm{~m} / \mathrm{s}]$} & \multicolumn{3}{|c|}{ values $d r[-]$} \\
\hline & & $t_{I P I}$ & $t_{I P 2}$ & $t_{D R}$ & $v_{p I P I}$ & $v_{p I P 2}$ & $v_{p D R}$ & $d r_{I P I}$ & $d r_{I P 2}$ & $d r_{D R}$ \\
\hline MC1035 & & 4.3 & 8.5 & 12.3 & 1490 & 2390 & 3040 & 0.042 & 0.121 & 0.281 \\
\hline MC1040 & & 5.3 & 11.0 & 12.8 & 1430 & 2360 & 2650 & 0.032 & 0.156 & 0.213 \\
\hline \multirow{3}{*}{ MC1050 } & MT1 & 7.2 & 12.5 & 14.6 & 1420 & 2040 & 2280 & 0.059 & 0.152 & 0.199 \\
\hline & MT2 & 5.8 & 10.4 & 13.4 & 1320 & 2090 & 2440 & 0.088 & 0.236 & 0.353 \\
\hline & MT3 & 5.1 & 8.3 & 8.5 & 1350 & 2020 & 2200 & 0.086 & 0.225 & 0.260 \\
\hline $\mathrm{MC} 2, \mathrm{MF} 1, \mathrm{MC} 3 \mathrm{~A} 1$ & & 6.7 & 8.9 & 14.1 & 1520 & 1760 & 2250 & 0.070 & 0.119 & 0.245 \\
\hline $\mathrm{MC} 3, \mathrm{MC} 3 \mathrm{~A} 2$ & & 7.7 & 10.0 & 16.7 & 1370 & 1740 & 2240 & 0.059 & 0.086 & 0.179 \\
\hline MC4, MF2 & & 4.5 & 7.6 & 9.2 & 1450 & 2180 & 2610 & 0.076 & 0.171 & 0.232 \\
\hline MF3 & & 4.9 & 8.1 & 10.2 & 1400 & 1970 & 2500 & 0.062 & 0.145 & 0.230 \\
\hline MC3A3 & & 7.1 & 9.0 & 16.5 & 1370 & 1650 & 2480 & 0.067 & 0.097 & 0.238 \\
\hline
\end{tabular}

\subsection{Estimation of the initial setting time of cement pastes with combined ultrasonic method}

Initial and final setting time are considered as two critical points during cement hydration. In this study, initial and final setting times were determined with standard Vicat method [23]. Penetration tests were performed at regular time intervals until the cement paste was completely set. The mean values of readings from three batches were used to define the initial $t_{V I}$ and final $t_{V F}$ setting time of each cement paste mixture. The results are summarized in Table 4 . In the table $\left(v_{p V I}, v_{p V F}\right)$ and $\left(d r_{V I}, d r_{V F}\right)$ stand for values of $\left(v_{p}, d r\right)$ at times $\left(t_{V I}, t_{V F}\right)$, respectively.

In comparing the results of Table 3 and 4 it can be seen that the times $t_{I P I}$ of the first inflection point on the $d r-v_{p}$ curves correspond very well with the initial setting time $t_{V I}$ for all cement paste mixtures at the same (room) temperature, investigated in this study. This is in a good agreement with the results obtained by Robeyst et al. [12]. Detailed description of this phenomenon can be found in ref. [11]. Therefore, it follows that the beginning of the setting process of an arbitrary cement paste could be indicated as the end of the first (horizontal) phase on the corresponding $d r-v_{p}$ curve. At times $t_{I P I}\left(\approx t_{V I}\right)$ the value $v_{p V I}$ reaches the ultrasonic speed of p-wave in water $(1430 \mathrm{~m} / \mathrm{s})$ and the values of $d r$ start to increase rapidly. Next, it can be seen that the $v_{p V F}$ values are quite similar for all cement paste mixtures at the same temperature. A convenient approach would be to define the final setting time as the time when the $v_{p}$ value reaches a value of about $1650 \mathrm{~m} / \mathrm{s}$, which is the average of 8 samples in Table 4 . This means that the final Vicat setting time occurs within the second phase of the $d r-v_{p}$ curve. A similar observation is not found with $d r$ results. 
Table 4

Initial and final setting time data for all cement paste mixtures, used in this study

\begin{tabular}{cccccccc}
\hline mixture & \multicolumn{2}{c}{ setting times [hours] } & \multicolumn{2}{c}{ values $v_{p}[\mathrm{~m} / \mathrm{s}]$} & \multicolumn{2}{c}{ values $d r[-]$} \\
label & & $t_{V, I}$ & $t_{V, F}$ & $v_{p V I}$ & $v_{p V F}$ & $d r_{V I}$ & $d r_{V F}$ \\
\hline MC1035 & & 4.6 & 5.5 & 1510 & 1630 & 0.044 & 0.053 \\
MC1040 & & 5.4 & 6.8 & 1430 & 1640 & 0.034 & 0.049 \\
& MT1 & 7.1 & 9.0 & 1420 & 1600 & 0.054 & 0.085 \\
MC1050 & MT2 & 5.8 & 6.6 & 1320 & 1480 & 0.088 & 0.113 \\
& MT3 & 5.1 & 5.8 & 1350 & 1420 & 0.086 & 0.119 \\
MC2, MF1, MC3A1 & & 6.7 & 8.4 & 1520 & 1680 & 0.070 & 0.108 \\
MC3, MC3A2 & & 7.9 & 9.5 & 1400 & 1660 & 0.060 & 0.079 \\
MC4, MF2 & & 4.4 & 5.5 & 1450 & 1680 & 0.074 & 0.103 \\
MF3 & 5.0 & 6.5 & 1420 & 1630 & 0.063 & 0.099 \\
MC3A3 & 7.3 & 8.9 & 1410 & 1640 & 0.069 & 0.095 \\
\hline
\end{tabular}

\section{Conclusions}

The correlation between the ultrasonic wave transmission method and ultrasonic wave reflection method in their ability to monitor the setting process of an arbitrary cement paste was analyzed. From the investigations described in this paper, the following conclusions can be drawn:

1. Both USWT and USWR methods are able to reliably monitor the hydration process and formation of structure of an arbitrary cement paste. Measurements with both USWT and USWR methods conducted on cement pastes with different hydration kinetics, evaluated on a qualitative basis, yield similar results.

2. Direct relationship between $v_{p}$ and $d r$ values reveals that the two ultrasonic methods monitor the setting process of cement pastes in different ways. Two inflection points were observed on the $v_{p}$ $-t$ curves and only one on the $d r-t$ curves.

3. The maximum rate in $v_{p}$ evolution appears earlier than the maximum rate of evolution of $d r$.

4. The experimental $d r-v_{p}$ diagrams can be simplified into three characteristic phases. Almost a horizontal line during the phase 1 indicates that p-wave speed $v_{p}$ is very sensitive to the internal structure of the cement paste at the very beginning of the hydration process. On the contrary, the differences in the internal structure of the cement paste do not seem to influence the initial values of the shear wave reflection coefficient.

5. When the amount of the solid phase reaches a certain value, the rate of $v_{p}$ increase slows down. However, at this point the $d r$ values keep on increase even more.

6. Using combined USWT - USWR ultrasonic method, the beginning of the setting process of an arbitrary cement paste can be determined by the end of the first phase on the $d r-v_{p}$ curve. 


\section{Acknowledgements}

The work of G. Trtnik has been financially supported by the Ministry of Education, Science and Sport, of the Republic of Slovenia, under contract 3211-05-000556. The support is gratefully acknowledged.

\section{References}

[1] J. Stepišnik, M. Lukač, I. Kocuvan, Measurement of cement hydration by ultrasonics, American Cheramic Socety Bulletin 60 (4) (1981) 481-483.

[2] M.I. Valič, Hydration of cementitious materials by pulse echo USWR. Method, apparatus and application examples, Cement and Concrete Research 30 (10) (2000) 1633-1640.

[3] Y. Akkaya, T. Voigt, K.V. Subramaniam, S.P. Shah, Nondestructive measurement of concrete strength gain by an ultrasonic wave reflection method, Materials and Structures 36 (262) (2003) 507-514.

[4] T. Voigt, T. Malonn, S.P. Shah, Green and early age compressive strength of extruded cement mortar monitored with compression tests and ultrasonic techniques, Cement and Concrete Research 36 (5) (2006) 858-867.

[5] T. Voigt, Z. Sun, S. P. Shah, Comparison of ultrasonic wave reflection method and maturity method in evaluating early-age compressive strength of mortar, Cement and Concrete Composites 28 (4) (2006) $307-316$.

[6] Z. Sun, T. Voight, S. P. Shah, Rheometric and ultrasonic investigations of viscoelastic properties of fresh Portland cement pastes, Cement and Concrete Research 36 (2) (2006) 278-287.

[7] Z. Sun, G. Ye, T. Voigt, S.P. Shah, K. Van Breugel, Early age properties of Portland cement pastes investigated with ultrasonic shear waves and numerical simulation, In RILEM International Symposium of Advances in Concrete through Science and Engineering, 2004.

[8] H. W. Reinhardt, C. U. Grosse, Continuous monitoring of setting and hardening of mortar and concrete, Construction and building materials 18 (3) (2004) 145-154.

[9] C. U. Grosse, H. W. Reinhardt, New developments in quality control of concrete using ultrasound, Non-Destructive Testing in Civil Engineering, International Symposium NDT-CE (2003).

[10] T. Kamada, S. Uchida, K. Rokugo, Non-destructive evaluation of setting and hardening of cement paste based on ultrasonic propagation characteristics, Journal of Advanced Technology 3 (3) (2005) 343-353.

[11] G. Trtnik, G. Turk, F. Kavčič, V. Bokan Bosiljkov, Possibilities of using the ultrasonic wave transmission method to estimate initial setting time of cement paste, Cement and Concrete Research 38 (11) (2008) 1336-1342. 
[12] N. Robeyst, E. Gruyaert, C.U. Grosse, N. De Belie, Monitoring the setting of concrete containing blast-furnace slag by measuring the ultrasonic p-wave velocity, Cement and Concrete Research 38 (10) (2008) 1169-1176.

[13] M. Krauss, K. Hariri, Determination of initial degree of hydration for improvement of early-age properties of concrete using ultrasonic wave propagation, Cement and Concrete Composites 28 (4) (2006) 299-306.

[14] T. Voigt, C. U. Grosse, Z. Sun, S. P. Shah, H. W. Reinhardt, Comparison of ultrasonic wave transmission and reflection measurements with P- and S-waves on early age mortar and concrete, Materials and Structures 38 (2005) 729-738.

[15] K. van Breugel, Simulation of hydration and formation of structure of hardening cement-based materials, PhD Theses, Delft, 1991.

[16] C.J. Korhonen, Off-the Shelf Antifreeze Admixtures, Cold Region Research and Engineering Laboratory, April 2002.

[17] A.K. Schindler, T. Dossey, B.F. McCullough, Temperature control during construction to improve the long term performance of portland cement concrete pavements. Texas Department of Transportation, Research project No. 0-1700-2, The University of Texas at Austin, 2002.

[18] J. R. Rapoport, J. S. Popovics, V. K. Subramaniam, S. P. Shah, Using ultrasound to monitor stiffening process of concrete with admixtures, ACI Mater. J. 97 (2000) 675-683.

[19] J. Keating, D. J. Hannant, A. P. Hibbert, Comparison of shear modulus and pulse velocity techniques to measure the build-up of structure in fresh cement pastes used in oil well cementing, Cement and Concrete Research 19 (4) (1989) 554-566.

[20] C. M Sayers, R. L. Grenfell, Ultrasonic propagation through hydrating cements, Ultrasonics 31, (3) (1993) 147-153.

[21] G. Ye, Experimental study and numerical simulation of the development of microstructure and permeability of cementitious materials, PhD Theses, Delft, 2003.

[22] P. C. Hewwlett, Lea's Chemistry of Cement and Concrete, Elsevier, Burlington MA, 2004.

[23] EN 19-3:2005, Methods of testing cement - Part 3: Determination of setting times and soundness, April 2005. 